\title{
Assessment of age with mandibular first molar: An orthopantogram study
}

\section{Ocena wieku na podstawie obrazu na zdjęciu pantomograficznym pierwszego dolnego zęba trzonowego}

\author{
Siddharth Mehta ${ }^{1, A-F}$, Arun S. Urala ${ }^{1, A}$, Vineetha R. ${ }^{2, B}$, Anjali Mehta ${ }^{3, D}$, Surendra Lodha ${ }^{4, E}$ \\ 1 Department of Orthodontics, Manipal College of Dental Sciences, Manipal University, Manipal, India \\ 2 Department of Oral Medicine and Radiology, Manipal College of Dental Sciences, Manipal University, Manipal, India \\ 3 Private Practitioner, Manipal, India \\ ${ }^{4}$ Private Practitioner, Bhilwara, India \\ A - research concept and design; $\mathrm{B}$ - collection and/or assembly of data; $\mathrm{C}$ - data analysis and interpretation; \\ $\mathrm{D}$ - writing the article; $\mathrm{E}$ - critical revision of the article; $\mathrm{F}$ - final approval of article
}

Address for correspondence

Siddharth Mehta

E-mail: sidmehta100@gmail.com

\section{Funding sources}

none declared

\section{Conflict of interest}

none declared

\section{Acknowledgements}

We wish to extend our sincere gratitude to Shreemathi S Mayya, associate professor, Department of Statistics, Manipal University and Deepak Singhal, reader, Department of Public Health Dentistry, Manipal University, for helping us in the statistical aspects of the study.

Received on January 28, 2017

Revised on April 17, 2017

Accepted on May 17, 2017

\begin{abstract}
Background. Assessment of age plays an important role in identifying living beings as well as the dead. Comparing different body parts for age estimation, teeth show the least changes after death and can also be checked in living individuals. This helps in forensics as well as in studying growth.

Objectives. The aim of this study was assess the age for Indian individuals from mandibular first molars using orthopantogram.

Material and methods. Orthopantograms were obtained from 370 Indian subjects in the age group $6-40$ years. The subjects were randomly divided into 2 samples; a study sample $(n=240)$ and a test sample $(n=130)$. A regression equation to calculate age was generated from the PCTHR (pulp chamber crown root trunk height ratio) and applied on the test sample to check for reliability of the equation.
\end{abstract}

Results. There was a significant negative correlation between actual age and PCTHR ( $r=-0.765$ : $p=<0.0001$ ) in the study group. The regression equation generated from the study sample was calculated age $=-94.627 \times(P C T H R)+43.585$. When used on the test sample, the calculated age showed no statistically significant difference with the actual age $(p=0.076)$. The mean difference between actual and calculated age was $3.275 \pm 2.188$ years.

Conclusions. The method of using PCTHR can be applied correctly to assess the age of Indian individuals.

Key words: age assessment, pulp height, mandibular molar, orthopantogram

Słowa kluczowe: ocena wieku, wysokość miazgi, ząb trzonowy, zdjęcie pantomograficzne

D0I

$10.17219 / \mathrm{dmp} / 73836$

Copyright

C 2017 by Wroclaw Medical University

and Polish Dental Society

This is an article distributed under the terms of the

Creative Commons Attribution Non-Commercial License

(http://creativecommons.org/licenses/by-nc-nd/4.0/) 
Assessment of age plays an important role in identifying living beings as well as the dead. ${ }^{1,2}$ Comparing different body parts for age estimation, teeth show the least changes after death and can also be checked in living individuals. $^{3}$

Age can be assessed in children by studying the different phases of root completion according to the Demirjian method. ${ }^{4}$ In adults, the same can be achieved by studying the parameters of attrition, periodontitis, secondary dentin deposition, cementum apposition, root resorption and transparency. ${ }^{5}$

Dental pulp size can also be used to assess the age of an individual as the size of the pulp chamber reduces with time due to deposition of secondary dentin and is not influenced by environment. ${ }^{6}$ Kvaal et al. assessed age with pulp size using periapical radiographs. ${ }^{7}$ Since taking periapical radiograph is time consuming and difficult, the same result can be achieved by utilizing a digital orthopantogram, which is a panoramic view of the upper and lower dentition and jaw.

Therefore, the present study was performed to assess age for Indian individuals using orthopantogram for age prediction. The objectives were to check for a relationship between age and pulp chamber to tooth size values, and to assess the variation of calculated age to the actual age of a test sample.

\section{Materials and methods}

Orthopantogram (OPG) is taken as a pretreatment record for orthodontic treatment. Anonymized digital orthopantograms of 370 patients in the age group 8-40 years who had registered for orthodontic treatment were selected from the records of the department. The subjects were divided randomly into 2 groups - a study sample of 240 patients and a test sample of

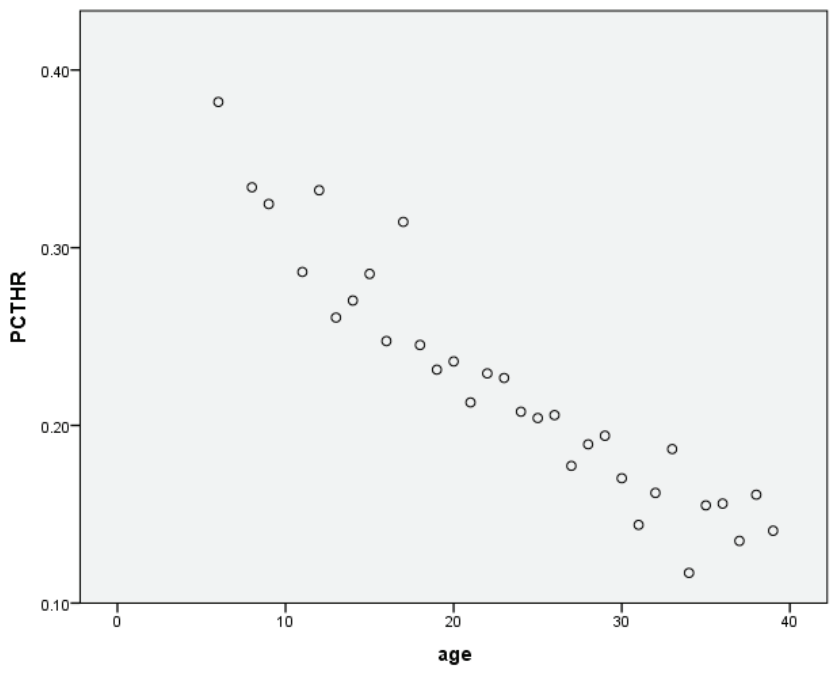

Fig. 1. Scatter diagram of PCTHR to actual age of study sample $(n=240)$
Table 1. Age and sex distribution of study subjects

\begin{tabular}{|c|c|c|c|c|c|}
\hline \multirow{3}{*}{ Age group } & \multicolumn{4}{|c|}{ Sex } & \multirow{3}{*}{ Total } \\
\hline & \multicolumn{2}{|c|}{ male } & \multicolumn{2}{|c|}{ female } & \\
\hline & $\mathrm{n}$ & $\%$ & $n$ & $\%$ & \\
\hline $0-9$ & 6 & 54.5 & 5 & 45.5 & 11 \\
\hline $10-19$ & 36 & 55.4 & 29 & 44.6 & 65 \\
\hline $20-29$ & 63 & 49.2 & 65 & 50.8 & 128 \\
\hline $30-39$ & 22 & 61.11 & 14 & 38.89 & 36 \\
\hline Total & 127 & 52.9 & 113 & 47.1 & 240 \\
\hline
\end{tabular}

130 patients. In each orthopantogram, a mandibular first molar was randomly chosen. Attrited, fractured, impacted, carious, heavily filled, RCT molars and orthodontically treated molars with bands were not included in the study. The study was approved by the Institutional Ethics Committee.

\section{Measurement}

Orthopantograms of 240 subjects were taken as a study population (males = 127; females = 113; Table 1). Digimizer $^{\circledR}$ Software (MedCalc Software, Belgium) was used to mark the points and document measurements in the digital orthopantogram (Fig. 1). Linear measurements were obtained for 2 parameters:

1. The distance between the central fossa and the highest point on the root furcation was the crown root trunk height (CRTH) and;

2. The distance between the roof and floor of the pulp chamber was the pulp chamber height $(\mathrm{PCH})$.

A ratio was derived between the pulp chamber height and crown root trunk height referred to as the pulp chamber crown root trunk height ratio $(\mathrm{PCH} / \mathrm{CRTH}=\mathrm{PCTHR})$. All measurements were recorded by a single observer and 40 randomly selected radiographs were measured a month later to check intra-observer variability.

All statistical analysis was performed using the software package SPSS for Windows version 10. Association between age and PCTHR was calculated using Pearson's correlation. A regression equation to calculate age was derived from PCTHR (study sample = 240; 127 males, 113 females). This equation was then applied on the test sample (130; 62 males, 68 females). The difference between the actual age and calculated age was calculated using a paired $\mathrm{t}$ test and documented as error. A p $<0.05$ was considered to be statistically significant.

Table 2. Mean and median age of study sample

\begin{tabular}{|c|c|c|}
\hline Study Sample & $n=240$ & SD \\
\hline Mean & 22.42 & \pm 6.910 \\
Median & 21 & - \\
\hline
\end{tabular}






Fig. 2. Measurements done on orthopantogram

Table 3. Calculation of regression equation

\begin{tabular}{|c|cc|c|c|c|}
\multirow{2}{*}{ Value } & \multicolumn{2}{|c|}{$\begin{array}{c}\text { Unstandardized } \\
\text { Coefficients }\end{array}$} & \multirow{2}{*}{$\begin{array}{c}\text { Standardized } \\
\text { Coefficients } \\
\text { Beta }\end{array}$} & t & Sig. \\
\cline { 2 - 3 } & $\mathrm{B}$ & Std. Error & & & \\
\cline { 1 - 3 } (Constant) & 43.585 & 1.190 & & 36.630 & .000 \\
Ratio & -94.627 & 5.162 & -.765 & -18.331 & .000 \\
\hline
\end{tabular}

Dependent variable: age.

Table 4. Age and sex distribution of study subjects

\begin{tabular}{|c|c|c|c|c|c|}
\hline \multirow{3}{*}{ Age group } & \multicolumn{4}{|c|}{ Sex } & \multirow{3}{*}{ Total } \\
\hline & \multicolumn{2}{|c|}{ male } & \multicolumn{2}{|c|}{ female } & \\
\hline & $n$ & $\%$ & $n$ & $\%$ & \\
\hline 10-19 & 13 & 36.1 & 23 & 63.9 & 36 \\
\hline $20-29$ & 31 & 50.0 & 31 & 50.0 & 62 \\
\hline $30-39$ & 18 & 56.2 & 14 & 43.8 & 32 \\
\hline Total & 62 & 47.7 & 68 & 52.3 & 130 \\
\hline
\end{tabular}

Table 5. Comparison of actual and calculated age (Paired t-test)

\begin{tabular}{|c|c|c|c|c|c|}
\hline Variable & $\mathrm{n}$ & Mean & SD & t-value & P-value \\
\hline Actual age & 130 & 24.38 & 6.875 & & \\
Calculated age & 130 & 23.764 & 5.933 & 1.791 & 0.076 \\
Mean difference & 130 & 0.613 & 3.90 & & \\
Absolute difference* $^{*}$ & 130 & 3.275 & 2.188 & $\min =0.00$ & $\max =9.53$ \\
\hline
\end{tabular}

Median $=23$ (actual age)

Table 6. Sex-wise comparison of chronological and predicted age (Paired t-test)

\begin{tabular}{|c|c|c|c|c|c|}
\hline Variable & $\mathrm{n}$ & Mean & SD & t-value & P-value \\
Male & & & & & \\
Actual age & 62 & 25.030 & 7.188 & & \\
Calculated age & 62 & 24.417 & 6.283 & 1.246 & 0.217 (NS) \\
Mean difference & 62 & 0.616 & 3.89 & & \\
Absolute difference & 62 & 3.309 & 2.095 & $\min =0.06$ & $\max =9.53$ \\
Female & & & & & \\
Actual age & 68 & 23.78 & 6.572 & & \\
Calculated age & 68 & 23.169 & 5.57 & 1.277 & 0.206 (NS) \\
Mean difference & 68 & .610 & 3.94 & & \\
Absolute difference & 68 & 3.24 & 2.285 & $\min =0.00$ & $\max =9.16$ \\
\hline
\end{tabular}

Results

The mean and median age of the study sample were $22.42 \pm 6.91$ years and 21 years, respectively (Table 2). A statistically significant negative correlation was obtained between age and PCTHR, suggesting the ratio of pulp to tooth height decreases with age $(r=-0.765$ : $\mathrm{p}=<0.0001$; Fig. 1). A regression equation was calculated by using linear regression function in SPSS and keeping age of the study sample as a dependent variable (Table 3). The formula derived from the study sample was: calculated age $=-94.627 \times($ PCTHR $)+43.585$,

$$
\left(\mathrm{r}^{2}=0.585\right) \text {. }
$$

This regression equation was then applied on the test sample (130; 62 males, 68 females; Table 4). The mean and median age of the test sample were $24.38 \pm 6.875$ years and 23 years, respectively. No statistically significant difference was seen between calculated age and actual age $(\mathrm{p}=0.076)$. The mean of absolute difference between actual and calculated age was 3.275 years \pm 2.188 (Table 5, 6). For males, the difference was found to be $3.309 \pm 2.095$ years whereas for females it was $3.24 \pm 2.285$ years (Table 4 ). This difference was less than 6 years in $87.7 \%$ of the subjects. The maximum difference between the 2 ages was 9.53 years (Table 7), which was within the acceptable limit for forensic age estimation $(< \pm 10$ years $){ }^{8}$ There was also no significant difference between the 2 ages in male and female test subjects, showing equal applicability to either gender.

Table 7. Table of percentage distribution of test subjects and absolute difference in years

\begin{tabular}{|c|c|c|c|c|}
\hline $\begin{array}{c}\text { Absolute difference } \\
\text { in years (actual age } \\
\text { - calculated age) }\end{array}$ & Male & Female & $\begin{array}{c}\text { Total } \\
\text { frequency }\end{array}$ & $\%$ \\
\hline 0.00-2 years & 15 & 27 & 42 & 32.4 \\
2-4 years & 30 & 19 & 49 & 37.7 \\
4-6 years & 10 & 13 & 23 & 17.6 \\
6-8 years & 5 & 7 & 12 & 9.2 \\
8-9.53 years & 2 & 2 & 4 & 3.1 \\
Total & 62 & 68 & 100 & 100.0 \\
\hline
\end{tabular}




\section{Discussion}

Knowledge of age plays a huge role in identification of the dead. A variety of invasive and non-invasive techniques are available for forensic age assessment. The advantage of non-invasive methods is that they can be applied to the living as well as the dead. Compared to various skeletal and sexual maturity parameters, age assessment with dental parameters shows less variability. ${ }^{9}$

Human dentition undergoes developmental and degenerative changes with age. ${ }^{5,10}$ Developmental changes noting stages of mineralization of the crown and root are useful in age prediction in early years. Degenerative changes include attrition, changes in pulp, tooth color and periodontium. Thus, our study accounts degenerative changes in pulp as the age advances.

Most of the studies ${ }^{3,4,11}$ dealing with radiological age estimation are applied only in subjects with developing teeth (Demirjian, Cameriere and Nolla systems). The age group selected in our study was from 8 to 40 years. Inference from the results suggests that this method can be applied irrespective of young or old age and thus has forensic as well as educational value.

Previous studies $3,7,12$ on age estimation with pulp to tooth height ratio have been applied on anterior teeth. Since molars are the first permanent teeth to erupt in the oral cavity, these teeth were chosen for the purpose of forensic age estimation in our study. In molars, the size of the pulp chamber reduces due to secondary dentin deposition on the roof and floor, thereby affecting the height and not width, with age. ${ }^{6}$

In a previous study by Drusini et al., the tooth coronal index was calculated by measuring the length of coronal pulp cavity at the highest point of the pulp horn to length of crown. ${ }^{13}$ In our study, the ratio of height of pulp chamber to height of crown root trunk was taken, which is easier to calculate compared to the method given by Drusini et al., since it is difficult to accurately appreciate coronal pulp chamber and CEJ. ${ }^{13}$

In our study, the ratio of pulp to tooth height decreased with age, so a significant negative correlation was seen between the 2 variables $(r=-0.765)$. Similar to the results of previous studies ${ }^{2,14,15}$ done on an Indian population, the value of the correlation was higher, suggesting digital orthopantogram and mandibular first molars are reliable in assessing the age of an individual.

There was no statistically significant difference between the age of the patient and age calculated with the regression equation $(\mathrm{p}=0.076) .87 .7 \%$ of the entire test sample showed less than 6 years as the absolute difference between the ages. Thus, radiographic assessment of the reduction in the size of the pulp chamber provides a relatively accurate, non-invasive method of age prediction irrespective of gender.

Limitations of this method are missing or presence of carious or heavily filled molars and examiner variability.

\section{Conclusion}

The method of using a ratio of pulp chamber to tooth height can be applied correctly to assess the age of Indian individuals.

\section{References}

1. Saxena S. Age estimation of Indian adults from orthopantomographs. Braz Oral Res. 2011;25:225-229.

2. Mathew DG, Rajesh S, Koshi E, Priya LE, Nair AS, Mohan A. Adult forensic age estimation using mandibular first molar radiographs: A novel technique. J Forensic Dent Sci. 2013;5:56-59.

3. Cameriere R, Ferrante L, Belcastro GM, Bonfiglioli B, Rastelli E, Cingolani M. Age estimation by pulp/tooth ratio in canines by peri-apical X-rays. J Forensic Sci. 2007;52:166-170.

4. Demirjian, A, Goldstein H, Tanner JM. A new system of dental age assessment. Human Biol. 1973;45:211.

5. Gustafson G. Age determination on teeth. J Am Dent Assoc. 1950;41:45-54.

6. Star H, Thevissen P, Jacobs R, Fieuws S, Solheim T, Willems G. Human dental age estimation by calculation of pulp-tooth volume ratios yielded on clinically acquired cone beam computed tomography images of monoradicular teeth. J Forensic Sci. 2011;56(Suppl 1):S77-82.

7. Kvaal SI, Kolltveit KM, Thomsen IO, Solheim T. Age estimation of adults from dental radiographs. Forensic Sci Int. 1995;74:175-185.

8. Solheim T, Sundnes PK. Dental age estimation of Norwegian adults - A comparison of different methods. Forensic Sci Int. 1980;16:e7-17.

9. Tavrianos C, Mastagas D, Stavrianou I, Karaiskou O. Dental age estimation of adults: A review of methods and principals. Res J Med Sci. 2008;2:258-268.

10. Rothwell BR. Principles of dental identification. Dent Clin North Am. 2001;45:253-270.

11. Nolla CM. The development of permanent teeth. J Dent Child. 1960;27:254-266.

12. Babshet $M$, Acharya $A B$, Naikmasur VG. Age estimation in Indians from pulp/tooth area ratio of mandibular canines. Forensic Sci Int. 2010;197:125.e1-4.

13. Drusini AG, Toso O, Ranzato C. The coronal pulp cavity index: A biomarker for age determination in human adults. Am J Phys Anthropol. 1997;103:353-363.

14. Limdiwala PG, Shah JS. Age estimation by using dental radiographs. J Forensic Dent Sci. 2013; 5:118-122.

15. Shah PH, Venkatesh R. Pulp/tooth ratio of mandibular first and second molars on panoramic radiographs: An aid for forensic age estimation. J Forensic Dent Sci. 2016;8:112-115. 